\title{
ANTHROPOMETRIC CHARACTERISTICS, BODY COMPOSITION AND FITNESS PROFILE OF SERBIAN CYCLIST MILAN MILIVOJEVIĆ: CASE STUDY
}

\author{
Ratko Pavlovići ${ }^{i}$, \\ Milan Milivojević2, \\ Nikolina Gerdijan ${ }^{3}$ \\ ${ }^{1}$ Faculty of Physical Education and Sport, \\ University of East Sarajevo, \\ Bosnia and Herzegovina \\ ${ }^{2}$ Cycling Club "Borac" Čačak, \\ Serbia \\ ${ }^{3}$ Faculty of Physical Education and Sport, \\ University of Banja Luka, \\ Bosnia and Herzegovina
}

\begin{abstract}
:
Cycling is one of the most demanding sports in terms of aerobic ability. Individual profiling, selection of cyclists implies adequate analysis of anthropometric characteristics and body composition. In addition to the analysis of anthropometric characteristics and body composition, it is necessary to detect and assess motor (physical) abilities, which are often defined by the term fitness profile. In this study, the anthropometric space, body composition and fitness abilities of cyclist M.M, a member of the Cycling Club "Borac" from Čačak and a member of the Serbian national team were analyzed in detail. As many as 60 variants were measured to assess the defined segments (anthropometric space, body composition, fitness profile). The obtained results of anthropometry and physical status confirmed the presence of the ectomorphic-mesomorphic somatotype of the cyclist, which is represented in the so-called road disciplines and endurance disciplines. Also, the fitness profile of the competitor determines extremely good results in all motor skills. To conclude that in addition to the dominance of aerobic abilities, cyclists define exceptional parameters of anaerobic abilities and fitness (motor) abilities (strength, speed, coordination, ...) and their pronounced synergistic effect.
\end{abstract}

Keywords: anthropometric characteristics, body composition, fitness abilities, detection, evaluation

\footnotetext{
${ }^{i}$ Correspondence: email pavlovicratko@yahoo.com
} 


\section{Introduction}

Cycling, along with Nordic running and marathon, is one of the most demanding sports in terms of aerobic abilities, and due to its prevalence around the world, it is considered a planetary sport. The development of modern cycling and the first bicycle races are related to Paris. Today, the world's most famous bicycle race (Tour de France) began in 1903. According to the rules of the World Cycling Federation (UCI), competitions are held on the road (road cycling), on the track (Track), cyclo-cross competitions, mountain bike competitions (mountain bike - MTB), bicycle moto-races (bicycle moto cross "BMX") and cyclo-tourism competitions. Each of the disciplines uses a different type of bicycle and equipment for cyclists, which is adapted to specific conditions (Nikolić, 2018).

According to Dopsaj, Nikolić, Mazić, et al. (2010) the most represented bicycle competitions in the world are road competitions, where within one-day road competitions for world championships up to $280 \mathrm{~km}$ are won, for the World Cup up to $250 \mathrm{~km}$, while for other road races the section is $200 \mathrm{~km}$. Compared to other competitions, the distances that cyclists cover are in the range of $200 \mathrm{~m}$ for sprint competitions on the track, then the so-called stage races lasting from 4 to 10 days, all the way to professional three-week races up to $5000 \mathrm{~km}$ long, the so-called tours, i.e. multi-week road competitions such as the "Tour de France", the "Giro d'Italia" and the "Vuelta a Espana" (Mujika, \& Padilla, 2001). It is very important to understand the specificity of road cycling due to the fact that the distances are of different duration and terrain configuration. In the $250 \mathrm{~km}$ road stage, the plain and mountain terrain configurations are represented, so that most world-class cyclists participate in a combination of these different configurations and specialties. In today's conditions, world-class professional cyclists cover an average of 35,000 km to 45,000 km in one season (Coyle, Feltner, Kautz, et al., 1991; Mujika, \& Padilla, 2001; Lucia, Hoyos, \& Chicharro, 2003), between 800 and 1,200 hours, while amateur national cyclists cover 15,000 to $18,000 \mathrm{~km}$ in the same period (Lucia, Hoyos, J., and Chicharro, 2001), between 350 and 500 hours (Friel, 2003). In professional cycling, 93min and $123 \mathrm{~min}$ are spent in races on mostly flat terrain on mountain stages, which are at an intensity of $70 \% \mathrm{VO}^{2} \mathrm{max}$. In addition, cyclists perform on an individual chronometer, which lasts about 20 minutes in the zone of anaerobic load (Perez, Fernandez-Garcia, \& Rodriguez-Alonso, 2002). According to Štimec (2015) in 2012, the Englishman Bradley Wiggins is the overall winner of the Tour de France, but also the Olympic individual time trial (2004 and 2008) in the individual time trial on the $4 \mathrm{~km}$ bike path, which leads to the conclusion that the individual time trial is $4 \mathrm{~km}$ on the cycle path an appropriate test to assess the competitive performance of cyclists. Most often, coaches in larger clubs in developed countries distinguish several specialties of cyclists based on morphological structure and functional abilities of athletes, riders who are successful in flat trial riding, riders on hill terrain (hill climbing), riders who are prepared to ride on different terrain riding configurations (all terrain riding), sprinter riders who have the ability to finish the sprint race after several hours to take the winning position and riders who are time trial racing specialists who have the ability to ride on 
upper limit of aerobic capacity over a long period of time (Padilla, Mujika, \& Cuesta, 1999; Menaspa, Rampinini, \& Bosio, 2012).

Numerous studies deal with the impact, studying and analyzing the anthropometric characteristics, functional abilities of cyclists in order to reach the relevant parameters that are necessary in cycling for a successful outcome. Identification of objective indicators on the basis of which it would be possible to determine the specialty of cyclists is very important, because it would help trainers in practice to optimize the training process and adapt the methodology of their preparation to the morpho-functional type of individual cyclists (Rauter, Milič, Žele, et al., 2015). Somatotype and individual anthropometric characteristics differ depending on the specialization of the cyclist, i.e. the length of the track they drive. According to Knechtle, Rosemann, Wirth \& Knechtle, (2009) anthropometric parameters correlate with race speed while training volume shows no significant correlation. It turns out that anthropometry has a greater impact on racing performance than training volume. Most studies have measured more anthropometric parameters that could relate to athlete performance. Only a few anthropometric parameters have been shown to be useful for identifying talent and development programs in several sports (Brunkhorst, \& Kielstein, 2013). The results of the research of anthropometric characteristics (McLean, Parker, 1989) on 35 elite male cyclists (sprinters and long-distance riders) on the track show that it is mainly an ectomorphic-mesomorphic somatotype that it is mainly an ectomorphicmesomorphic somatotype (height $178 \pm 4.8 \mathrm{~cm}$ and average weight $72.5 \pm 6.6 \mathrm{~kg}$ ). There was a significant correlation between strength and body weight $(\mathrm{r}=0.57)$ and thigh circumference $(\mathrm{r}=0.55)$. No significant correlation was observed between any anthropometric parameter and performance in a single event. Bicyclists in the sprint group were heavier (76.2 vs. 70.0) and stronger (258 vs. $216 \mathrm{Nm}$ ) and had higher chest (96.2 vs. $92.4 \pm 2.9 \mathrm{~cm})$, arm circumference (33.0 vs. $30.7 \mathrm{~cm})$, thigh $(57.5$ vs. $54.3 \mathrm{~cm}$ ) and lower leg circumference 37.8 vs. $36,2 \mathrm{~cm}$ ) than cyclists in the endurance group. They were also more mesomorphic (5.3 vs. 4.7 ) and less ectomorphic (2.3 vs. 2.9$)$ than endurance cyclists.

The aim of the study Brunkhorst, \& Kielstein (2013) was to compare several anthropometric parameters and subjective characteristics of professional elite triathletes with anthropometric profiles of professional cyclists and sportive students. Eight different anthropometric parameters were measured and a five-page questionnaire containing 35 general questions had to be completed. Interestingly, there were no significant differences between the arm span, the lengths of the lower limb and the circumference of the waist and hip between male triathletes and cyclists. As expected, the athletes had significantly lower heart rates and lower weights as compared to the controls. Further results showed that male cyclists had a higher BMI, larger thighs and were taller as compared to the male triathletes. The present study could not evaluate specific anthropometric characteristics as predictive factors of performance in elite athletes. Thus, individual successful performance is linked to discipline and talent rather than to a specific anthropometric profile. 
Authors Dopsaj, et al. (2010) define the profile of preparedness of cyclists in the junior category and determine the differences in functional indicators in cyclists who perform in different competitive disciplines: road cyclist, mountain riders, and sprinters. The results show that the maximum oxygen consumption of national cyclists of junior category $\left(\mathrm{VO}^{2} \mathrm{max}=56.42 \pm 5.82 \mathrm{ml} \bullet \mathrm{min}-1 \mathrm{~kg}-1\right)$ was measured, where $\mathrm{VO}^{2} \mathrm{max}=61.43 \pm 4.94$ was measured for hillers, $56.78 \pm 3.33$ for sprinters, and $53.37 \pm 7.82$ for tempo riders. The analysis of the obtained results showed that there were no significant differences between the sample of cyclists at the general level in relation to the functional indicators. These results lead to the conclusion that the tested athletes were trained by applying general training, because although they predominantly compete in different disciplines, the level of preparedness indicates that the training process used in cycling in Serbia in juniors does not imply specific training in the competitive discipline. Studies Impellizzeri \& Marcora (2007) report an average heart rate during competitions close to $90 \%$ of the maximum (HRmax), corresponding to $\approx 85 \%$ of maximal oxygen uptake $\left(\mathrm{VO}^{2} \mathrm{max}\right)$, and a large amount of time, $\approx 40 \%$ of total race time, spent in a high-intensity domain, above the power at individual anaerobic threshold (Stapelfeldt, Schwirtz, Schumacher, et al., 2004). In addition, due to the significant involvement of anaerobic metabolism authors suggest the importance of anaerobic power and capacity indices in the requirements of cycling.

Also, monitoring body composition (BC), and especially regional adiposity, can identify patterns associated with athletic performance and health (Ackland, Lohman, Sundgot-Borgen, et al. 2012). Although BC can reflect many factors unrelated to physical activity and training, it is common knowledge that specific low or high adiposity itself can affect many different sports and cyclist performance (Alvero-Cruz, García Romero, Ordonez, et al., 2022). Knowing the regional adiposity and profile of BC athletes can be very useful for coaches, for example, in improving development programs for their athletes and in longitudinal monitoring of changes in BC athletes, which may indicate athletic fitness (Legaz, 2005). Cycling training models are constantly evolving, and the results of top athletes are becoming more homogeneous, as shown by tables from the world cycling championships for professional cyclists in the disciplines: chronometer, cycle track (time trial) and mountain biking (MTB). The difference between the first and second place in the men's time trial is $2.5 \%$, and between the first and fifth place in the 4 $\mathrm{km}$ on the bike path is less than $0.5 \%$ of the total race time. In mountain biking, the difference between the first and tenth at the World Championships is less than $3 \%$, and the difference between the first and fiftieth riders on the Tour de France (race lasts 21 days, approx. 40 hours) is about $1 \%$ of the total race time. These data show that any small progress in the training process can significantly affect the sports result, i.e. competitive success (Štimec, 2015).

In the process of many years of training, there are seasonal variations in relation to the type of training and competition preparation of cyclists. A very important control of the level of current training of athletes involves periodic testing using standardized procedures, where the method of laboratory testing provides the most reference data on the state of training of athletes - cyclists (Peiffer, Abbiss, Chapman, et al. 2008). On the 
other hand, laboratory tests are non-specific in relation to the general conditions of the athlete, so the obtained data are optimal for assessing the level of morphological and motor development of the cyclist's body and body composition as a relevant factor in success (Dopsaj, et al. 2010). According to our information, there are no studies aimed at analyzing the anthropometric characteristics, physical status and fitness abilities of Serbian cyclists.

This is the first research (case study) with an individual, a cyclist (so-called "Road cyclist"), a member of BC "Borac" Čačak and the Serbian national team. The purpose of this case study was to analyze the anthropometric profile, body composition and fitness abilities that characterize it.

\section{Methods and Materials}

\subsection{The sample of participants}

The study was conducted with Milan Milivojević (M.M), Serbian cyclist (22 years old; Body height 185cm; Body weight 70kg; BMI 20,4kg/m²; Body fat 10,6\%; Body water 62,9\%; Body muscle 59,4kg; Heart pulse $=59 \mathrm{bpm}$, saturation $\mathrm{O}_{2}=98 \%$ ), a member of Cycling club "Borac" Čačak (Serbia), and the member Serbian national team. His 11 years in cycling sport. The aim of the study was to analyze Anthropometric characteristics (AC), Body composition (BC) and Fitness profile (FP).

\subsection{The sample of variables}

The total of 60 variables were variables of AC, BC and FP evaluations:

Table 1: The total of 60 variables

\begin{tabular}{|l|l|}
\hline Body height $(\mathrm{cm})$ & Basal metabolism $(\mathrm{kCal})$ \\
\hline Body weight $(\mathrm{kg})$ & Daily calorie intake $(\mathrm{kCal})$ \\
\hline Body mass index-(BMI $\left(\mathrm{kg} / \mathrm{m}^{2}\right)$ & Metabolic years \\
\hline Chest perimeter $(\mathrm{cm})$ & Visceral fat \\
\hline Upper arm perimeter $(\mathrm{cm})$ & Press-ups test (max.) \\
\hline Forearm perimeter $(\mathrm{cm})$ & Sit-ups test (max.) \\
\hline Abdomen perimeter $(\mathrm{cm})$ & Chin up test (max.) \\
\hline Upper leg perimeter $(\mathrm{cm}$ & Standing broad jump test $(\mathrm{m})$ \\
\hline Lower leg perimeter $(\mathrm{cm})$ & Triple jump standing $(\mathrm{m})$ \\
\hline Triceps skinfold $(\mathrm{mm})$ & Five jumps standing $(\mathrm{m})$ \\
\hline Biceps skinfold $(\mathrm{mm})$ & Run $15 \mathrm{~m}$ (sec.) \\
\hline Subscapular skinfold $(\mathrm{mm})$ & Run 30 (sec.) \\
\hline Suprailiac skinfold $(\mathrm{mm})$ & Run $100 \mathrm{~m}(\mathrm{sec})$. \\
\hline Abdomen skinfold $(\mathrm{mm})$ & HGS Right hand $(\mathrm{kg})$ \\
\hline Front thigh skinfold $(\mathrm{mm})$ & HGSLeft hand $(\mathrm{kg})$ \\
\hline Rear thigh skinfold $(\mathrm{mm})$ & Throwing the ball 3kg standing $(\mathrm{m})$ \\
\hline Body fat mass $(\%)$ & Throwing the ball 3kg sitting $(\mathrm{m})$ \\
\hline Body water $(\%)$ & Ball throwing speed with $7 \mathrm{~m}(\mathrm{~m} / \mathrm{s})$ \\
\hline Body muscle $(\mathrm{kg})$ & Leg strength test-jumps on one leg (sec.) \\
\hline Bones $(\mathrm{kg})$ & Sprint Bound index \\
\hline Right hand muscle $(\mathrm{kg})$ & Illinois agility run test $(\mathrm{sec})$. \\
\hline Left hand muscle $(\mathrm{kg})$ & Squat jump - SJ (cm) \\
\hline
\end{tabular}


FITNESS PROFILE OF SERBIAN CYCLIST MILAN MILIVOJEVIĆ: CASE STUDY

\begin{tabular}{|l|l|}
\hline \hline Torso muscle $(\mathrm{kg})$ & Countermovement jump-CMJ $(\mathrm{cm})$ \\
\hline Right leg muscle $(\mathrm{kg})$ & Countermovement jump with arm swing-CMJarm swing $(\mathrm{cm})$ \\
\hline Left leg muscle $(\mathrm{kg})$ & Stiffness test $(\mathrm{cm})$ \\
\hline Right hand fat $(\%)$ & Energy of elasticity \\
\hline Left hand fat $(\%)$ & Coordination index \\
\hline Torso fat $(\%)$ & Peak anaerobic power - SJPAP $(\mathrm{W})^{* * *}$ \\
\hline Right leg fat $(\%)$ & Peak anaerobic power - CMJPAP $(\mathrm{W})^{* * *}$ \\
\hline Left leg fat $(\%)$ & Peak anaerobic power- CMJarm PAP $(\mathrm{W})^{* * *}$ \\
\hline
\end{tabular}

\subsection{Experimental design}

Anthropometric measurements were performed according to the methodology of the International Society for the Assessment of Kinanthropometry - ISAK standard procedures. The standard metric instruments were applied: Stadiometer-used for measuring body height (SECA 206, Germany); flexible tape used for measuring the body perimeter and its segments. Body weight and Body Composition were assessed with the bioelectrical impedance method using a body composition analyser (Tanita InnerScanV BC-545N, Tokyo, JAPAN), in accordance with the measurement protocol. The Caliper for measuring skin folds (GIMA-model Plicometro, ITALY). All variables applied to the assessment of fitness profile according to (Bosco, Luhtanen, Komi, 1983; Sayers, Harackiewicz, Harman, et al. 1999; Mackenzie, 2005). Participant M.M provided oral informed consent prior to testing. All measurements were conducted during the month of May 2021., in accordance with the procedures of the Declaration of Helsinki.

\section{Results and Discussion}

The main goal of the study was to analyze the anthropometric profile, body composition and fitness profile of a cyclist M.M member of the cycling club "Borac" Čačak (Serbia) (Table 2, Figure 1-4). Specific physical characteristics (fitness), anthropometric profile, and body composition are required for the highest levels of performance in each cycling discipline (sprint, endurance, road, etc.).

Table 2: Measured parameters

\begin{tabular}{|l|c|}
\hline Measured parameters (AC, BC, $\mathbf{F P})$ & Value \\
\hline Body height $(\mathrm{cm})$ & 185 \\
\hline Body weight $(\mathrm{cm})$ & 70 \\
\hline BMI $(\mathrm{kg} / \mathrm{m} 2)$ & 20,40 \\
\hline Chest perimeter $(\mathrm{cm})$ & 88 \\
\hline Upper arm perimeter $(\mathrm{cm})$ & 29,5 \\
\hline Forearm perimeter $(\mathrm{cm})$ & 26 \\
\hline Abdomen perimeter $(\mathrm{cm})$ & 70 \\
\hline Upper leg perimeter $(\mathrm{cm})$ & 57 \\
\hline Lower leg perimeter $(\mathrm{cm})$ & 35 \\
\hline Triceps skinfold $(\mathrm{mm})$ & 10 \\
\hline Biceps skinfold $(\mathrm{mm})$ & 4 \\
\hline Subscapular skinfold $(\mathrm{mm})$ & 10 \\
\hline Chest skinfold $(\mathrm{mm})$ & 4,8 \\
\hline Abdomen skinfold $(\mathrm{mm})$ & 13 \\
\hline
\end{tabular}


Ratko Pavlović, Milan Milivojević, Nikolina Gerdijan

ANTHROPOMETRIC CHARACTERISTICS, BODY COMPOSITION AND

FITNESS PROFILE OF SERBIAN CYCLIST MILAN MILIVOJEVIĆ: CASE STUDY

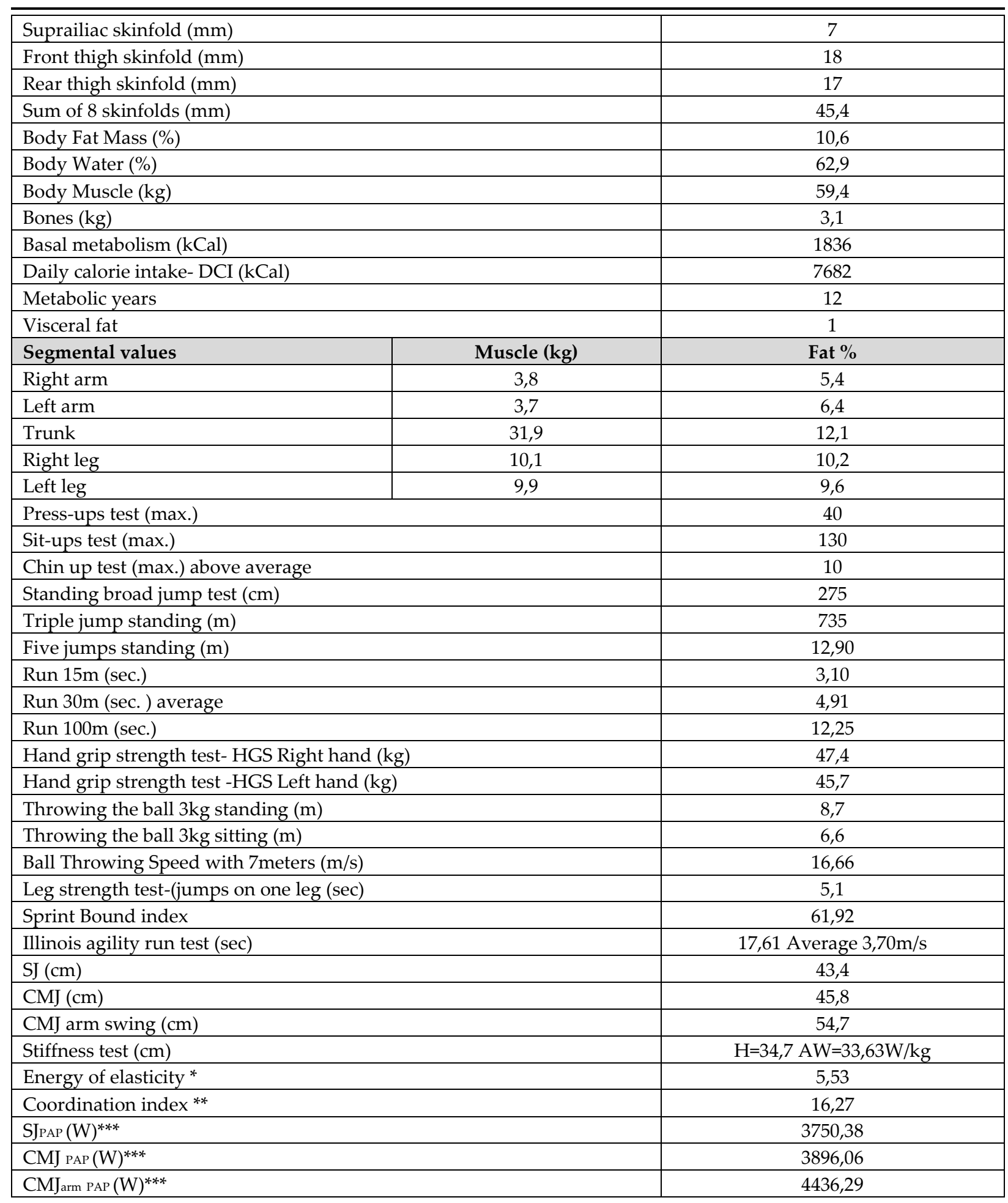

Note: *the formula is used ((CMJ-SJ)/CMJ)x100; **the formula is used ((ABK-CMJ)/ABK)x100

${ }^{* * *}$ The Sayers Equation: Peak anaerobic power output-PAPw $=(60.7 x$ jump height $(\mathrm{cm}))+(45.3 \times$ body mass $(\mathrm{kg}))-2055$. 


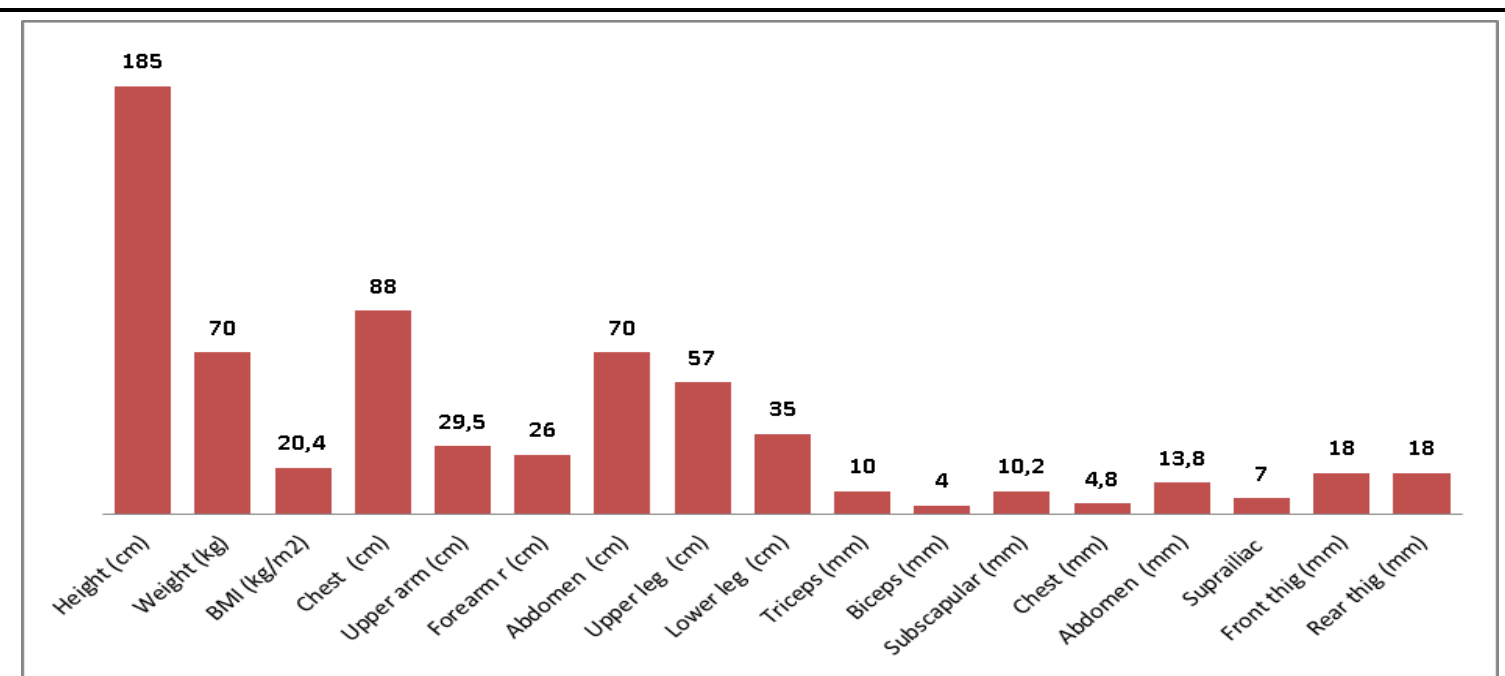

Figure 1: Anthropometric parameters

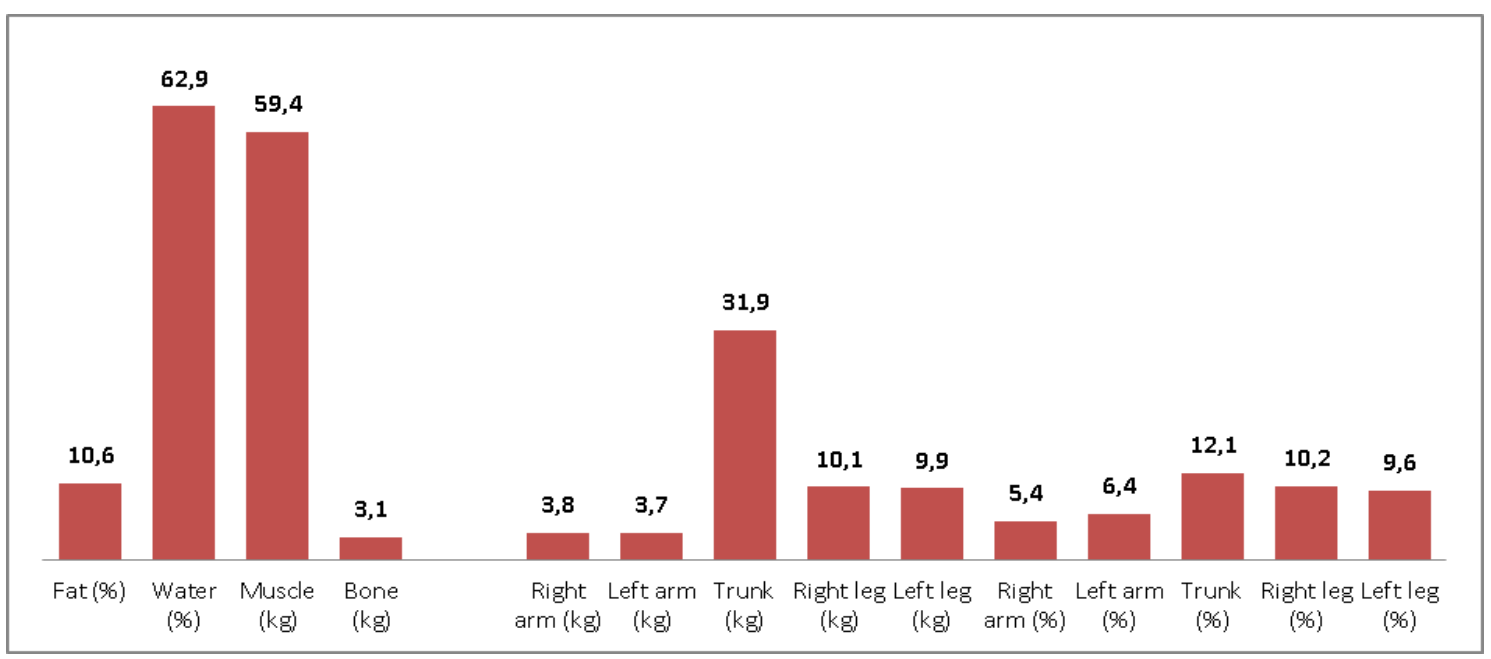

Figure 2: Body composition

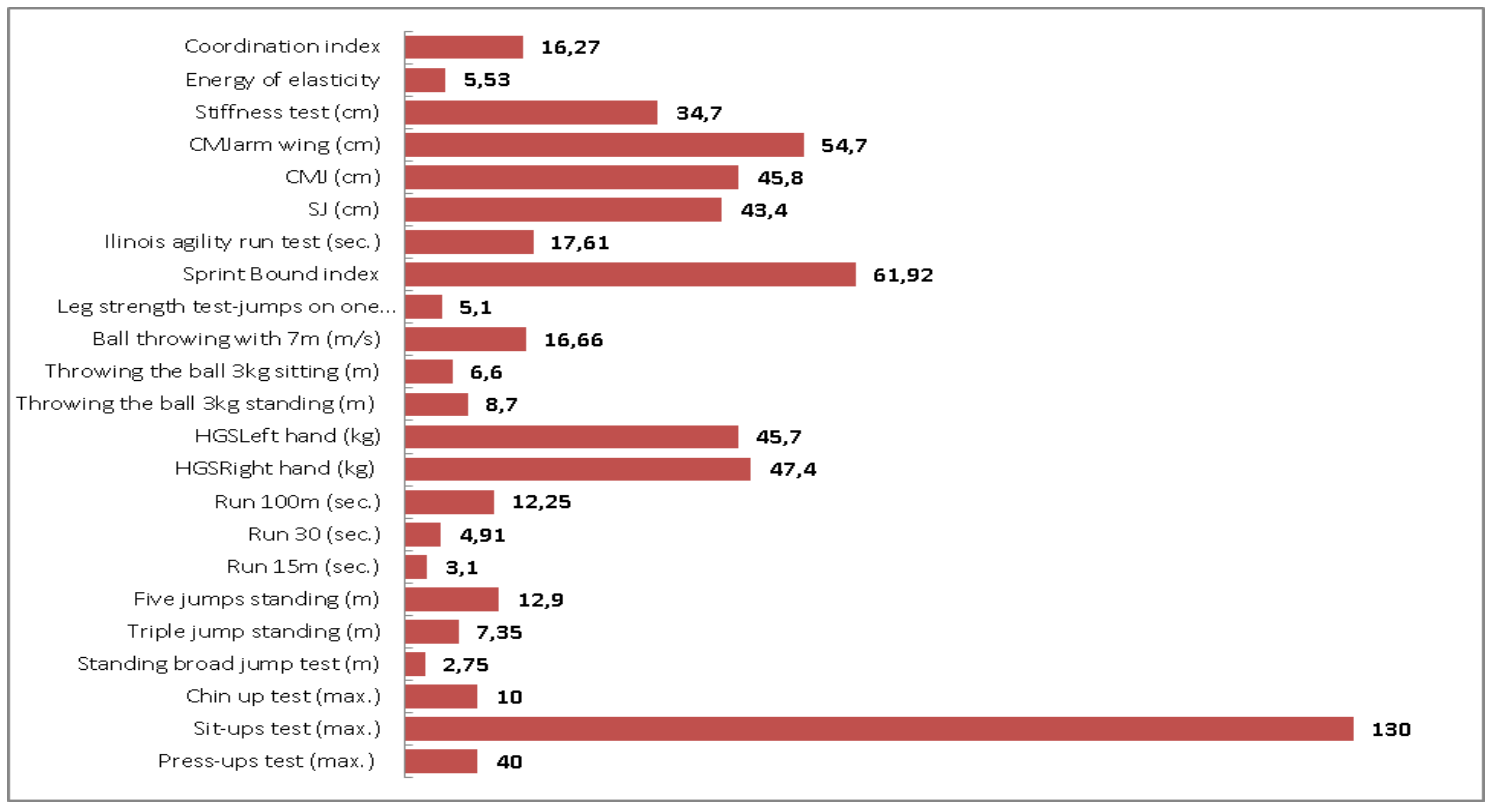

Figure 3: Fitness profile 


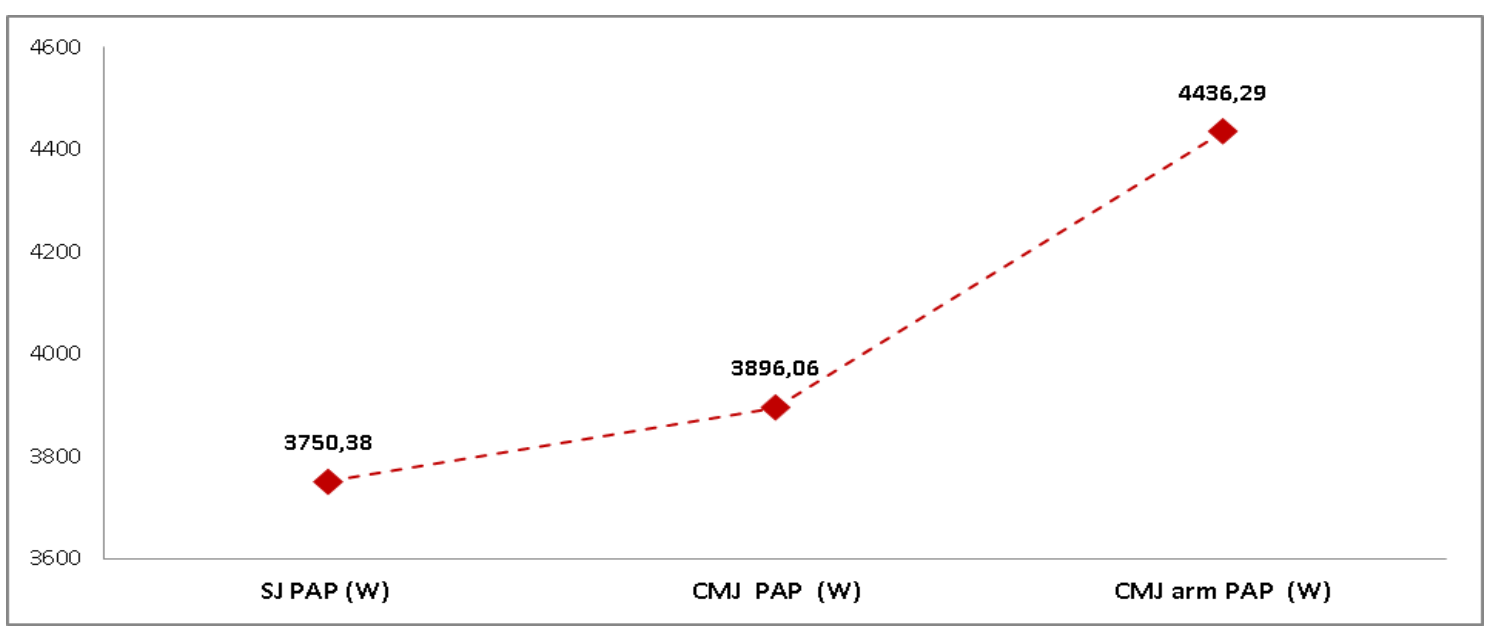

Figure 4: Peak anaerobic power output - PAP (W)

Anthropometric characteristics and athlete's physique of an individual athlete are considered to be an important determinant of success in many sports (Brunkhorst, \& Kielstein, 2013). Even though there are many determinants that contribute to the performance of athletes, most sports require a specific range in body size and shape to compete at the top level (Norton, \& Olds, 2001; van der Zwaard, de Ruiter, Jaspers, et al. 2019). Consequently, athletes tend to specialize toward sports disciplines that are well aligned with their anthropometry (Foley, Bird, \& White, 1989). In cycling, for example, athletes specialize into the disciplines sprint, pursuit, uphill, time trial, flat-terrain, and all-terrain, each demonstrating distinct anthropometric characteristics (Foley et al., 1989; Padilla, Mujika, Cuesta, et al. 1999; Mujika, \& Padilla, 2001; Menaspà et al., 2012). For instance, road climbers pursue a low body mass to enhance their uphill performance, as body mass increases the resistance from gravity. Flatterrain cyclists reduce their frontal area per body mass to improve performance during flat stages, minimizing relative energy costs to aerodynamic resistance (Mujika, \& Padilla, 2001).

Table 2 and Graphs (1-4) contain the results of anthropometric characteristics, body composition and fitness abilities of the studied sample. Anthropometric characteristics quantitatively and qualitatively define the corresponding ectomorphicmesomorphic somatotype where the average height $(185 \mathrm{~cm})$ with body weight $(70 \mathrm{~kg})$ and BMI $\left(20.40 \mathrm{~kg} / \mathrm{m}^{2}\right)$ are good indicators of pronounced longitudinality (in relation to body mass and volume) which is primary in endurance cycling. Body volume parameters are also within the limits that are dominant for this sample of cyclists and together with longitudinality significantly determine the ectomorphic somatotype. There is a significant difference between the cranial extremities with the following values (Upper arm perimeter $29.5 \mathrm{~cm}$; Forearm perimeter $26 \mathrm{~cm}$ ) in relation to the circumference of the caudal extremities (Upper leg perimeter $57 \mathrm{~cm}$; Lower leg perimeter $35 \mathrm{~cm}$ ). Skin folds also record lower values in the cranial extremity region. This is expected due to the fact that the total circumferences define the joint and the variance of body weight, which in this case is relatively small $(70 \mathrm{~kg})$, while the sum of 8 skin folds is $83.8 \mathrm{~mm}$. The body fats of 
our sample are also represented in a low percentage (10.6\%) and according to the tabular values they record a healthy level. The percentage of water in the muscles is about $63 \%$, which is a relevant indicator of good hydration and muscle function. Muscle mass participates with close to $60 \mathrm{~kg}(88.78 \%)$ of the total body weight and with a bone mass of $3.1 \mathrm{~kg}$. Most often, bone mass is not conditioned by BMI and weight of competitors, but by some other factors such as exposure to sunlight, calcium intake and individual habits such as diet (Atri, Malandish, Rashidlamir, et al. 2013).

The nutrition is a very important segment in cycling, because it manifests high energy consumption during the cycling race. The nutritional requirements of the training and competition programmes of elite endurance cyclists are challenging. Notwithstanding the limitations of dietary survey techniques, studies of high-level male road cyclists provide important information about nutrient intake and food practices during training and major stage races. Typically, male cyclists undertaking intensive training programmes report a high energy intake $(\geq 250 \mathrm{~kJ} / \mathrm{kg} /$ day $)$ and carbohydrate $(\mathrm{CHO})$ intakes of 8 to $11 \mathrm{~g} / \mathrm{kg} /$ day. Intakes of protein and micronutrients are likely to meet Recommended Dietary Intake levels, because of high energy intakes (Burke, 2001). It is very important that sports nutritionists design personalised diets in order to maintain a correct proportion of nutrients as well as controlling possible anthropometrical changes that could affect performance. The basal metabolism of cyclist records 1836kCal, while the daily consumption is $7682 \mathrm{kCal}$, defining together with all parameters of physical status (composition) the metabolic age of 12 years, which is 11 years less than his biological age and is an indicator of good shape and health. Body composition, and especially regional adiposity, identifies and influences patterns associated with cyclist sports performance (Ackland, Lohman, Sundgot-Borgen, et al., 2012; Alvero-Cruz, García Romero, Ordonez, et al. 2022) which may indicate sports fitness. In our cyclist (Figure 2) body composition is defined by a greater presence of muscle mass in the torso $(31.9 \mathrm{~kg})$, then almost equal values of caudal extremities (left leg $9.9 \mathrm{~kg}$ vs. right leg10.1 kg) and cranial extremities (left arm 3,7kg vs. right arm $3.8 \mathrm{~kg}$ ). Out of only $10.6 \%$ of body fat, the highest percentage is topographically occupied by the trunk region $(12.1 \%)$, slightly higher for caudal extremities (left leg $9.6 \%$ vs. right leg 10.2\%) and cranial extremities (left arm) $6.4 \%$ vs. right arm $5.4 \%$ ).

Cycling is a complex sport in which several physiological, mechanical and environmental factors can affect strength and speed. According to Swain (1994), it is sport in which an athlete's energy cost is related to two principal forces: air resistance when traveling on flat terrain, and gravity when traveling uphill. Both wind tunnel data and physiological measurements suggest that air resistance scales as body mass to about the $1 / 3$ power. Thus, large cyclists have only slightly greater frontal drags than small cyclists. If expressed relative to body mass, the frontal drag of small cyclists is considerably greater than that of large cyclists. The difference in frontal drag (energy cost) is not made up for by the advantage to small cyclists in relative VO2max (energy supply), since the mass exponent for drag (1/3) is closer to zero than that for VO2max (2/3). Professional cycle racing is one of the most demanding of all sports combining extremes of exercise 
duration, intensity, and frequency. Riders are required to perform on a variety of surfaces (track, road, cross-country, mountain), terrains (level, uphill, and downhill), and race situations (criteria, sprints, time trials, massstart road races) in events ranging in duration from $10 \mathrm{~s}$ to $3 \mathrm{wk}$ stage races covering $200 \mathrm{~m}$ to 4,000 km. Furthermore, professional road cyclists typically have $\sim 100$ race $\mathrm{d} / \mathrm{yr}$. Because of the diversity of cycle races, there are vastly different physics (motoric) and physiological demands associated with the various events (Jeukendrup, Craig, \& Hawley, 2000).

Track cycling competitions range from the $200 \mathrm{~m}$ sprint (10 to 11 seconds) to the $50 \mathrm{~km}$ race (about 1 hour). Unlike road cycling competitions where most races take place at submaximal power output, shorter track competitions require cyclists to maximize both the aerobic and anaerobic metabolic pathways. Elite cyclists on the track have key physical (motor) and physiological attributes that are in line with the specific requirements of their competitions, where above all they must have an appropriate genetic predisposition which is then maximized through effective training interventions (Craig, \& Norton, 2001)

Specific physical characteristics together with body composition are necessary for the highest levels of performance in cycling where energy power and economy of work are the main parameters. It is for this reason that the Fitness profile of the cyclist is very important and plays an important role in determining the potential for success within cycling disciplines. According to (Pavlović, Radulović, \& Savić, 2021), motor fitness defines the relationship between the central nervous system and muscles (neuromuscular coordination), which enables athletes to successfully perform activities. Specific components of fitness (agility, balance, coordination, strength, reaction time and speed) must be integrated in the best possible way, which is confirmed by the results of this study. Insight into the personal parameters of the cyclist shows that it is an enviable morphological status, body composition and functional parameters that suit cyclists.

In the current study, the values of the basic motor components of the cyclist are estimated, which are of great importance for the success of the athlete. Findings by authors (Sunde, Storen, Bjerkaas, et al. 2010; Park, Kim, Yoo, et al. 2019) suggest evidence that muscle mass, maximal muscle strength, and isokinetic muscle function are important predictors of cyclist performance in racing. The strength of the muscular chains of the cyclist's arms and shoulder girdle MM assessed by the maximum number of push-ups $(=40)$, torso lift $(=130)$, the number of pull-ups $(=10)$ are indicators of the good motor status of the cyclist and integrated upper (cranial) and lower (caudal) muscle chain body part, which supports the previous study. Cycling is a sport that is considered the dominant form of exercise in the lower part of the body that emphasizes the use of the quadriceps, knee tendons, gluteus, hip flexors, and to some extent $\mathrm{mm}$. gastrocnemius. In recent years, there has been significant research to determine which upper body (i.e. grip strength) contributes to high intensity during cycling efforts lasting $\leq 30$ sec.

Canivel, Randy, Wyatt, et al. (2012) proved that peripheral isometric contractions lead to improved power output during performance, i.e. that the upper body through hand grip and back strength helps stabilize the lower body during cycling, the so-called 
pedaling cycle (Dore, Baker, Jammes, et al. 2006, Hansen, Raastad, \& Hallén, 2007). In this regard, the estimated grip strength of our sample was estimated by dynamometry (right arm, $47.4 \mathrm{~kg}$ vs. left arm $45.7 \mathrm{~kg}$ ) and the results confirmed previous research on the synergistic effect of grip strength on lower body stabilization during the race. Bicycle racing is a sprint competition, where the power of pedaling that explodes in a short time is an important factor in determining the victory or loss of a competition (Atkinson, Peacock, St Clair Gibson, et al., 2007). Pedaling force is a force that is repeatedly applied to the pedals by the extensor and flexor muscles of the hip, knee, and ankle (McDaniel, Behjani, Elmer et al., 2014). Among the muscle fibers in the lower limbs, the strength of pedaling is influenced by the type of muscle and the volume of muscle fibers involved in pedaling, and is closely related to the coordination of the hips, knees, ankles, and external oblique abdominal muscles (Elmer Barratt, Korff, et al., 2011).

Sakamoto, Naito, \& Chow (2018), confirm that maximum and average strength in cyclists are highly correlated with maximum muscle strength around the knee and hip joint, and quadriceps strength, anaerobic strength and VO2max are key factors for success. It was the numerical parameters of different variants of vertical jumps $(\mathrm{SJ}=43.4 \mathrm{~cm}, \mathrm{CMJ}=45.8 \mathrm{~cm}$; CMJarm swing $=54.7 \mathrm{~cm}$ ) that defined and confirmed the good condition of the muscular kinetic chains of the caudal extremities and their synchronized action. This is also an indication that the explosiveness of the vertical type is significant. In the vertical jump test (Stiffness test 2/6) our rider recorded an average height of $34.7 \mathrm{~cm}$ with an average leg strength of $33.63 \mathrm{w} / \mathrm{kg}$. Also, the Peak anaerobic power output-PAP (Figure 4) of our competitor is of enviable value (SJPAP=3750.38w; CMJPAP=3896.06w and CMJarmpap $=4436.29 w$ ) which is in line with the cyclist's body weight and cycling discipline where the muscle output-dependent pedaling cycle (PAP) where the pedaling cycle produces movement of the knee joint by the strength of the tendon and gluteal muscle. Muscle activity in the gluteus and quadriceps muscle is high at a pedaling angle of $0^{\circ}-180^{\circ}$, and posterior lobe muscle activation increases to $181^{\circ}-360^{\circ}$ (Elmer et al., 2011; McDaniel et al., 2014). The importance of developing maximum muscle strength to improve athletic performance in most sports, including cycling, is generally accepted. During training and competition, the human body takes energy for activities depending on their intensity and duration, and most often the energy for muscle activity in cycling depends on the length of the track, which engages anaerobic or aerobic sources. It has been established that road cyclists belong to athletes with a highly developed aerobic energy system (Faria, Parker, Faria, 2005; Lucia, Hoyos, Perez, Santalla, Earnest, Chicharro, 2004; Sallet, Mathieu, Fenech, et al. 2006), however, the anaerobic system for extremely successful competition obtaining energy. The ability to achieve very high muscle strength in a short period of time is very important for situations such as mass start, mountain driving, as well as at the very end of the race where the rider sprints to the finish line for better placement is one of the factors a good competitive result also depends on (Wilber, Zawadzki, Kearney, Shannon, Disalvo, 1997; Padilla, et al. 1999).

In this regard, the state of explosiveness and speed of individual movement of the cranial extremities of our cyclist was assessed by throwing the ball $(=3 \mathrm{~kg})$ from a standing 
position $(=8.7 \mathrm{~m})$ and sitting position $(=6.6 \mathrm{~m})$ are good, given the body weight of our rider $(70 \mathrm{~kg})$. Also, the parameters of the explosiveness of the caudal extremities were estimated by long jump from the place $(=275 \mathrm{~cm})$, triple jump from the place $(=7.35 \mathrm{~m})$, five-jump from the place $(=12.90 \mathrm{~m})$, ball speed with $7 \mathrm{~m}(=16.66 \mathrm{~m} / \mathrm{s})$. The obtained results of the current measurement of our sample support the results of previous studies (Hansen et al., 2007; Hodges, 2003, Sunde et al. 2010)).

Due to the fact that the bicycle race in some parts of the sprint character (at the start of the race, during overtaking on the track, during the finish, etc.) sprint speed is extremely important, which is confirmed by the results of running at $15 \mathrm{~m}(=3.10 \mathrm{sec}),. 30 \mathrm{~m}$ $(=4.91 \mathrm{sec}),. 100 \mathrm{~m} \quad(=12.25 \mathrm{sec}$.$) which mobilizes phosphocreatine and glycolytic$ mechanisms (Table 1, Figure 3). This is an indication that sprinting abilities are very present in cyclists at the beginning of the race or at the very end when fast muscle fibers are activated. The achieved result of the Sprint bound index test $(\mathrm{SBI}=61.92)$ is a good indicator of strength and explosiveness in the caudal extremities of cyclists. Together with the values of the leg strength test (Leg strength test $=5.1 \mathrm{sec}$ ) it projects good strength which according to the tabular values corresponds to the result above the average (Mackenzie, 2005). Illinois agility test with time (Illinois=17.61sec) and average speed $(3.70 \mathrm{~m} / \mathrm{s})$ is an indicator that our cyclist has a well-developed so-called motor intelligence (agility), which largely depends on the degree of development of the central nervous system. The state of the central nervous system is characterized by a variable that we defined as the energy of elasticity whose value $(E E=5.53)$ corresponds to a good neuromuscular adaptation of the cyclist. Only the coordination index proved to be higher $(\mathrm{CI}=16.27)$. Elasticity plays a significant role in the pedaling cycle. If a tendon or active muscle is stretched, elastic energy is stored within these structures. This deformation energy is stored and used to improve motor output in the concentric relaxationcontraction phase. To improve cycling pedaling strength, it is necessary to implement a systematic training program for effective interaction of core strength and upper and lower muscular strength that can maintain posture while riding a bicycle (Hartmann, Wirth, Keiner et al., 2015; Rønnestad, \& Hansen, 2018). The torso stability exercise is a method of exercise that increases the maximum strength of the back, thigh and hip muscles, which suggests that this increased maximum strength can improve flexibility and balance, as well as shorten the ride for cyclists. According to various studies that have published a link between performance and torso strength in elite athletes, torso exercises increase the maximum strength of the hip flexor muscles and the range of motion in the hip joint. In addition to torso strength, basic physical fitness of the upper and lower body is another factor in deciding whether to win a cycling competition (Mujika, Rønnestad, Martin, et al., 2016; Rønnestad, Hansen, Hollan, et al., 2016). Based on the presented results, it follows that the cyclist's body is a complex cybernetic mechanism with good support of a closed muscle kinetic chain and different energy output mechanisms with adequate morphological status, body composition, and fitness abilities. 


\title{
4. Conclusion
}

The results of the study will help to understand the importance of anthropometric characteristics, physique, and fitness abilities of cyclists-competitors, which will be a kind of guide for trainers to adapt and understand the importance of these dimensions in cycling. The obtained results of anthropometry and physical status confirmed the ectomorphic-mesomorphic somatotype of the cyclist, which is represented in the socalled road disciplines and endurance disciplines. Also, the fitness profile reflects extremely good results in all motor skills. This leads to the conclusion that in addition to the dominance of aerobic abilities, cyclists define exceptional parameters of anaerobic abilities and fitness (motor) abilities (different types of strength, speed, coordination, ...) and their pronounced synergistic effect within a closed muscle kinetic chain.

\begin{abstract}
About the Author(s)
Ratko Pavlović is a Professor of Sports and Rehabilitation Sciences of University of East Sarajevo, Faculty of Physical Education and Sport. His current research interests are Track and Field, Kinanthropometry, Sports Science, Motor Skills, Isokinetic, Biomechanics of Sport (email: pavlovicratko@yahoo.com)

Milan Milivojevic, is a Master Student of Physical Education and Sport, University East Sarajevo. Member of the Cycling Club Borac "Čačak" and Coach of the Cycling Club "Era" Užice. Research interest areas: cycling (email: milivojevicmilan18@gmail.com)

Nikolina Gerdijan is an associate professor at University of Banja Luka, Faculty of physical education and sport, Republic of Srpska, BIH. 2014 she acquired the title Doctor of Science in Physical Education and Sport by defending a thesis on "Acute effect of static and dynamic stretching on maximal force and power of thigh muscles". She is researching in the field of kinesiotherapy, injury prevention, isokinetic, postural balance, movement analysis, pilates. (email: nikolina.gerdijan@ffvs.unibl.org)
\end{abstract}

\section{References}

Atkinson, G., Peacock, O., St Clair Gibson, A., \& Tucker, R. (2007). Distribution of power output during cycling: impact and mechanisms. Sports Med. 37, 647-667.

Atri, A. E., Malandish, A., Rashidlamir, A., \& Shabani, M. (2013). The Relationship between Body Weight, Body Mass Index (BMI) and Bone Mineral Density (BMD) of the Lumbar Spine and Femoral Neck in Professional Cyclists of Iran and Tourde-France. Iranian Journal of Health and Physical Activity, 4 (1), 67-71.

Ackland, T. R.; Lohman, T. G.; Sundgot-Borgen, J.; Maughan, R. J., Meyer, N. L.; Stewart, A. D., \& Mller, W. (2012). Current status of body composition assessment in sport: Review and position statement on behalf of the Ad Hoc research working group 
on body composition health and performance, under the auspices of the I.O.C. medical commission. Sport. Med. 42, 227-249.

Alvero-Cruz, J. R., García Romero, J. C., Ordonez, F. J., Mongin, D., Correas-Gómez, L., Nikolaidis, P. T., \& Knechtle, B. (2022). Age and Training-Related Changes on Body Composition and Fitness in Male Amateur Cyclists. International Journal of Environmental Research and Public Health. 19(1), 93. https://doi.org/10.3390/ijerph19010093

Bosco, C., Luhtanen, P., \& Komi, P. V. (1983). A simple method for measurement of mechanical power in jumping. Eur J Appl Physiol Occup Physiol. 50(2), 273-282. doi: 10.1007/BF00422166.

Burke, L. M. (2001). Nutritional practices of male and female endurance cyclists. Sports Med. 31(7), 521-32. doi: 10.2165/00007256-200131070-00007.

Brunkhorst, L. \& Kielstein, H. (2013). Comparison of anthropometric characteristics between professional triathletes and cyclists. Biol. Sport.30, 269-273

Coyle, E. F., Feltner, M. E., Kautz, S. A., Hamilton, M. T., Montain, S. J., Baylor, A. M., Abraham, L. D. \& Petrek, G. W. (1991). Physiological and biomechanical factors associated with elite endurance cycling performance. Medicine and science in sports and exercise. 23(1), 93-107.

Craig, N. P., \& Norton, K. I. (2001). Characteristics of track cycling. Sports Med. 31 (7), 457-468. doi: 10.2165/00007256-200131070-00001

Canivel, R. G., Wyatt, F. B., \& Baker, J. S. (2012). Cardiovascular responses to isometric hand grip vs. relaxed hand grip in sustained cycling efforts. J Strength Cond Res 26(11), 3101-3105.

Doré, E., Baker, J. S., Jammes, A., Graham, M., New, K., \& Van Praagh, E. (2006). Upper body contribution during leg cycling peak power in teenage boys and girls. Research in Sports Medicine, 14(4), 245-257. doi.org/10.1080/15438620600985829

Dopsaj, M., Nikolić, B., Mazić, S., \& Zlatković, J. (2010). Readiness Profile of Junior Cyclists Determined by Leipzig Test. Acta Medica Medianae .49(3), 32-39.

Elmer, S. J., Barratt, P. R., Korff, T., \& Martin, J. C. (2011). Joint-specific power production during submaximal and maximal cycling. Med Sci Sports Exerc. 43, 1940-1947.

Foley, J. P., Bird, S. R., \& White, J. A. (1989). Anthropometric comparison of cyclists from different events. Br. J. Sports Med. 23 (1), 30-33. doi: 10.1136/bjsm.23.1.30

Friel, J. (2003). The cyclist's training Bible, Third Edition. Boulder, Colorado: Velopress.

Faria, E. W., Parker, D. L., \& Faria, I. E. (2005). The science of cycling: physiology and training part 1. Sports Med. 35 (4),285-312.

Hodges, P. W. (2003). Core stability exercise in chronic low back pain. Orthop Clin North Am. 34, 245-254.

Hansen, E. A., Raastad, T., \& Hallén, J. (2007). Strength training reduces freely chosen pedal rate during submaximal cycling. Eur J Appl Physiol. 101, 419-426.

Hartmann, H., Wirth, K., Keiner, M., Mickel, C., Sander, A., \& Szilvas, E. (2015). Shortterm periodization models: effects on strength and speed-strength performance. Sports Med.45,1373-1386. 
Impellizzeri, F. M., \& Marcora, S. M. (2007). The physiology of mountain biking. Sports Medicine, 15 37(1), 59-71

Jeukendrup, A. E., Craig N. P., \& Hawley J. A. (2000). The bioenergetics of World Class Cycling. J Sci Med Sport. 3(4), 414-33. doi: 10.1016/s1440-2440(00)80008-0.

Knechtle, B., Rosemann, T., Wirth, A., \& Knechtle, P. (2009). Moderate Association of Anthropometry, But Not Training Volume, With Race Performance in Male Ultraendurance Cyclists. Research Quarterly for Exercise and Sport. 80 (3), 563-568.

Lucia, A., Hoyos, J., \& Chicharro, J. L. (2001). Physiology of professional road cycling. Sports Medicine, 31(5), 325-337.

Lucia, A., Hoyos, J. \& Chicharro, J. L. (2003). In High-Tech Cycling, Vol. Second (Ed., Burke, E.) Human Kinetics, Champaign, 265-288.

Lucia, A., Hoyos, J., Perez, M., Santalla, A., Earnest, C. P., \& Chicharro, J. L. (2004). Which laboratory variable is related with time trial performance time in the Tour de France? Br J Sports Med. 38(5), 636-640.

Legaz, A. (2005). Changes in performance, skinfold thickness, and fat patterning after three years of intense athletic conditioning in high level runners. Br. J. Sports Med. $39,851-856$.

McLean, B. D., \& Parker, W. (1989). An anthropometric analysis of elite Australian track $\begin{array}{llllll}\text { cyclists. Journal of Sport Sciences. } 7 & \text { (3), 247-255. }\end{array}$ https://doi.org/10.1080/02640418908729845

Mackenzie, B. (2005). 101 Performance Evaluation Tests. Published by: Electric Word plc. 67-71 Goswell Road London. https://www.brianmac.co.uk/eval.htm.

Mujika, I., \& Padilla, S. (2001). Physiological and performance characteristics of male professional road cyclists. Sports medicine, 31(7), 479-487.

Mujika, I., Rønnestad, B. R., \& Martin, D. T. (2016). Effects of increased muscle strength and muscle mass on endurance-cycling performance. Int J Sports Physiol Perform. 11, 283-289.

Menaspa, P., Rampinini, E., Bosio, A., Carlomagno, D., Riggio, M., \& Sassi, A. (2012). Physiological and anthropometric characteristics of junior cyclists of different specialties and performance levels. Scand J Medicine $\mathcal{E}$ Science in Sports $\mathcal{E}$ Exercise, 22(3), 392-398.

McDaniel, J., Behjani, N. S., Elmer, S. J., Brown, N. A., \& Martin, J. C. (2014). Joint-specific power-pedaling rate relationships during maximal cycling. J Appl Biomech.30, 423430.

Norton, K., \& Olds, T. (2001). Morphological evolution of athletes over the 20th century: causes and consequences. Sports Med.31, 763-783. doi: 10.2165/00007256200131110-00001

Nikolić, B. (2018). Determination of Cyclist Competition Speciality Features for Functional and Morphological Indicators. Unpublished Doctoral Dissertation. University Of Belgrade Faculty of Sport and Physical Education. 
Pavlović, R., Radulović, N., \& Savić, V. (2021). Fitness Profile of Uroš Gutić, Runner Middle and Long Distance: Case study. Journal of Advances in Sports and Physical Education. 4 (11), 219-224.

Peiffer, J. J., Abbiss C. R., Chapman D., Laursen P. B., \& Parker D. L. (2008). Physiological characteristics of master level cyclists. J Strength Cond Res. 22(5), 1434-1440.

Padilla, S., Mujika, I., Cuesta, G., \& Goiriena, J. J. (1999). Level ground and uphill cycling ability in professional road cycling. Medicine and science in sports and exercise, 31(6), 878-885.

Perez-Landaluce, J., Fernandez-Garcia, B., Rodriguez-Alonso, M., García-Herrero, F., García-Zapico, P., Patterson, A. M., \& Terrados, N. (2002). Physiological differences and rating of perceived exertion (RPE) in professional, amateur and young cyclists. The Journal of sports medicine and physical fitness, 42(4), 389-395.

Park, J. H., Kim, J. E., Yoo, J. I., Kim, Y. P., Kim, E. H., \& Seo, T. B. (2019). Comparison of maximum muscle strength and isokinetic knee and core muscle functions according to pedaling power difference of racing cyclist candidates. I Exerc Rehabil.15(3), 401-406. doi: 10.12965/jer.1938180.090.

Rauter, S., Milič, R., Žele, L., Hvastija, M., \& Vodičar, J. (2015). Laboratorijske meritve in kriteriji uspešnosti pri kolesarjih mlajših kategorij. Revija Za Teoreticna in Prakticna Vprasanja Sporta. 63, (1/2), 161-167.

Rønnestad, B. R., Hansen, J., Hollan, I., Spencer, M., \& Ellefsen, S. (2016). Impairment of performance variables after in-season strength-training cessation in elite cyclists. Int J Sports Physiol Perform. 11, 727-735.

Rønnestad, B. R., \& Hansen, J. (2018). A scientific approach to improve physiological capacity of an elite cyclist. Int J Sports Physiol Perform. 13, 390-393.

Swain, D. P. (1994). The influence of body mass in endurance bicycling. Medicine and science in 4 sports and exercise. 26(1), 58-63

Sayers, S. P., Harackiewicz, D. V., Harman, E. A., Frykman, P. N., \& Rosenstein, M. T. (1999). Cross-validation of three jump power equations. Medicine and Science in Sports and Exercise. 31(4), 572-577. doi: 10.1097/00005768-199904000-00013.

Stapelfeldt, B., Schwirtz, A., Schumacher, Y. O., \& Hillebrecht, M. (2004). Workload demands in mountain bike racing. International Journal of Sports Medicine, 25(4), 294-300.

Sallet, P., Mathieu, R., Fenech, G., \& Baverel, G. (2006). Physiological differences of elite and professional road cyclists related to competition level and rider specialization. The Journal of sports medicine and physical fitness. 46(3), 361-365.

Sunde, A., Storen, O., Bjerkaas, M., Larsen, M. H., Hoff, J. \& Helgerud, J. (2010). Maximal strength training improves cycling economy in competitive cyclists. Journal of Strength and Conditioning Research, 24(8), 2157-2165.

Sakamoto, A., Naito, H., \& Chow, C. M. (2018). Effects of hyperventilation on repeated pedaling sprint performance: short vs. long intervention duration. J Strength Cond Res. 32, 170-180. 
Štimec, B. (2015). The influence of a specific respiratory training on parameters of competitive success in nationally ranked cyclists. Unpublished Doctoral Thesis. Faculty of Kinesiology. Zagreb.

Wilber, R. L., Zawadzki, K. M., Kearney, J. T., Shannon, M. P., \& Disalvo, D. (1997). Physiological profiles of elite off-road and road cyclists. Med Sci Sports Exerc. 29 (8), 1090-1094.

van der Zwaard, S., de Ruiter, C. J., Jaspers, R. T., \& de Koning, J. J. (2019). Anthropometric Clusters of Competitive Cyclists and Their Sprint and Endurance Performance. Frontiers in physiology. 10 1276. https://doi.org/10.3389/fphys.2019.01276. 
Ratko Pavlović, Milan Milivojević, Nikolina Gerdijan

ANTHROPOMETRIC CHARACTERISTICS, BODY COMPOSITION AND

FITNESS PROFILE OF SERBIAN CYCLIST MILAN MILIVOJEVIĆ: CASE STUDY

Creative Commons licensing terms

Authors will retain the copyright of their published articles agreeing that a Creative Commons Attribution 4.0 International License (CC BY 4.0) terms will be applied to their work. Under the terms of this license, no permission is required from the author(s) or publisher for members of the community to copy, distribute, transmit or adapt the article content, providing a proper, prominent and unambiguous attribution to the authors in a manner that makes clear that the materials are being reused under permission of a Creative Commons License. Views, opinions and conclusions expressed in this research article are views, opinions and conclusions of the author(s). Open Access Publishing Group and European Journal of Physical Education and Sport Science shall not be responsible or answerable for any loss, damage or liability caused in relation to/arising out of conflict of interests, copyright violations and inappropriate or inaccurate use of any kind content related or integrated on the research work. All the published works are meeting the Open Access Publishing requirements and can be freely accessed, shared, modified, distributed and used in educational, commercial and non-commercial purposes under a Creative Commons attribution 4.0 International License (CC BY 4.0). 